\title{
Organización para la vida: Relaciones recíprocas en las ventas ambulantes josefinas desde la perspectiva de la economía popular
}

\author{
Nancy Solís
}

United World College Costa Rica, Costa Rica

nancy.solis@uwccostarica.org

Resumen: Partiendo del concepto de economía popular, este trabajo pretende acercar al lector a la cotidianidad de los vendedores y vendedoras ambulantes josefinos, esbozando el ambiente de la venta ambulante y definiendo las estructuras organizadas alrededor de esta actividad. La convivencia, la recolección de relatos y una revisión de su memoria histórica permitieron concluir que las ventas ambulantes no son solamente una alternativa de sustento ante las condiciones excluyentes de la formalidad. Es un oficio heredado que se disfruta muchas veces y permanece a pesar de las duras circunstancias en las calles del San José caóticamente ordenado.

Palabras clave: Antropología Urbana, barriada, economía popular, ventas ambulantes, San José.

Organizations towards life: Mutual relations among peddlers in San José from the popular economy perspective

Abstract: Starting from the concept of popular economics, this work aims to bring the reader into the daily life of San José peddlers. Sharing with them experiences in their work spaces and by a review of its historical memory, it is concluded that street vending is not only an alternative to exclusive conditions of formal economy. It is more an inherited practice, which is enjoyed most of the times and remains on the chaotically - organized San José streets, despite the harsh circumstances.

Keywords: Urban Anthropology, cantred, popular economic, peddlers, street sales, San José.

Cuadernos de Antropología 2014, 24(2), 73-95

Recibido: 03-09-2014 / Aceptado: 13-11-2014

Revista del Laboratorio de Etnología María Eugenia Bozzoli Vargas Escuela de Antropología, Universidad de Costa Rica

http://revistas.ucr.ac.cr/index.php/antropologia

ISSN 2215-356X

cC) (i) (-) Cuadernos de Antropología está bajo una licencia Creative Commons EY NG SA Attribution-NonCommercial-ShareAlike 3.0

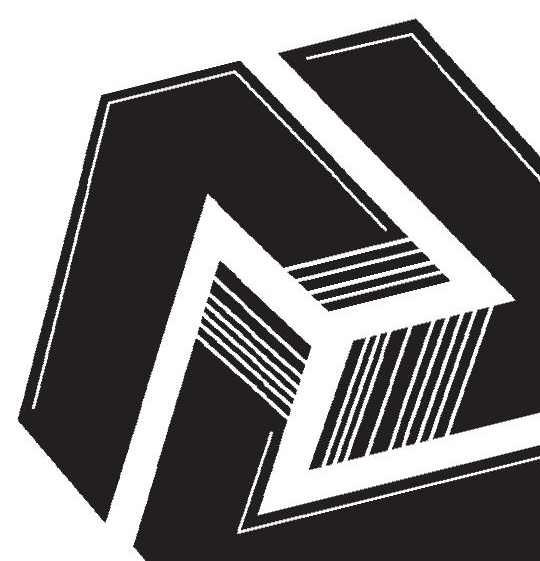




\section{Introducción}

Este trabajo analiza la cotidianidad de los vendedores ambulantes de frutas y vegetales en las inmediaciones del Mercado Central y Mercado Borbón, San José, Costa Rica, desde la perspectiva de la economía popular. Se tomaron en cuenta las relaciones y organización que surgen alrededor de la venta ambulante y que construyen su modo de vida, donde no solo se vende en la calle por necesidad económica, sino también por tradición familiar o gusto. En todo momento, la intención será asignarle un rostro humano a este oficio nómada, donde las vivencias de quienes lo ejercen pueden ir "pintando" un barrio, una comunidad donde se manifiesta la economía popular en respuesta a la pobreza, pero esta "no entendida como conjunto de carencias, déficit y necesidades, sino como permanente iniciativa social creadora y soberanía residual potenciada al máximo" (Salazar, 2003, p. 10).

Las ideas en torno a este tema están estructuradas en tres ejes. Primero, se realiza un esbozo del ambiente de esa economía popular en San José y en donde parece haber una estructura barrial inserta, pues toda una cotidianidad se desarrolla entre calles, edificios, vegetales y frutas. Posteriormente, se hace un análisis de la venta ambulante y el modo de vivirla dentro de este gremio a partir de la noción de economía popular, noción que posibilita ampliar la perspectiva desde la cual se ha explicado tradicionalmente esta actividad. Finalmente, se toma la intervención de la autoridad municipal como elemento de fractura de esa economía popular y, a la vez, se retoman los códigos y organización de los vendedores para enfrentar la amenaza de los decomisos o "quiebres".

Para lograr recolectar la información necesaria para la elaboración de este escrito, se realizaron observaciones etnográficas en el lugar de trabajo de los vendedores y poder así "descifrar" el uso del espacio y el desarrollo laboral del día a día. Las entrevistas a profundidad no estructuradas, en el contexto inmediato, facilitaron un acercamiento estrecho a las vivencias de ellos y ellas, en sus actividades económicas, que también son su modo de vida, su espacio de recreo, de educación y socialización. La Machita, Noé, Conrado y Esperanza aportaron su amplia experiencia como vendedores a la construcción de este bosquejo de la barriada en medio del "caos ordenado" josefino. El trabajo de campo se llevó a cabo entre los meses de diciembre del 2010 y enero y febrero del 2011. Los cuatro informantes mencionados anteriormente fueron las figuras claves para la elaboración de este trabajo.

\section{La calle, la barriada}

Gritos de oferta con voz ronca. Hombres y mujeres ofrecen chiles, plátanos, culantro, ajos, mandarinas, aguacates, a las reinitas, los negros y mi'amores que transitan en las aceras y calles (Figura 1). Estrategia corta y directa: se anuncia el producto y el precio. ¡Chile dulce, diez en quinientos, diez en quinientos! ¡Tome papi pa'que le lleve a la doña y le haga la comida, chile diez en quinientos!. El cliente solo pregunta

http://revistas.ucr.ac.cr/index.php/antropologia 


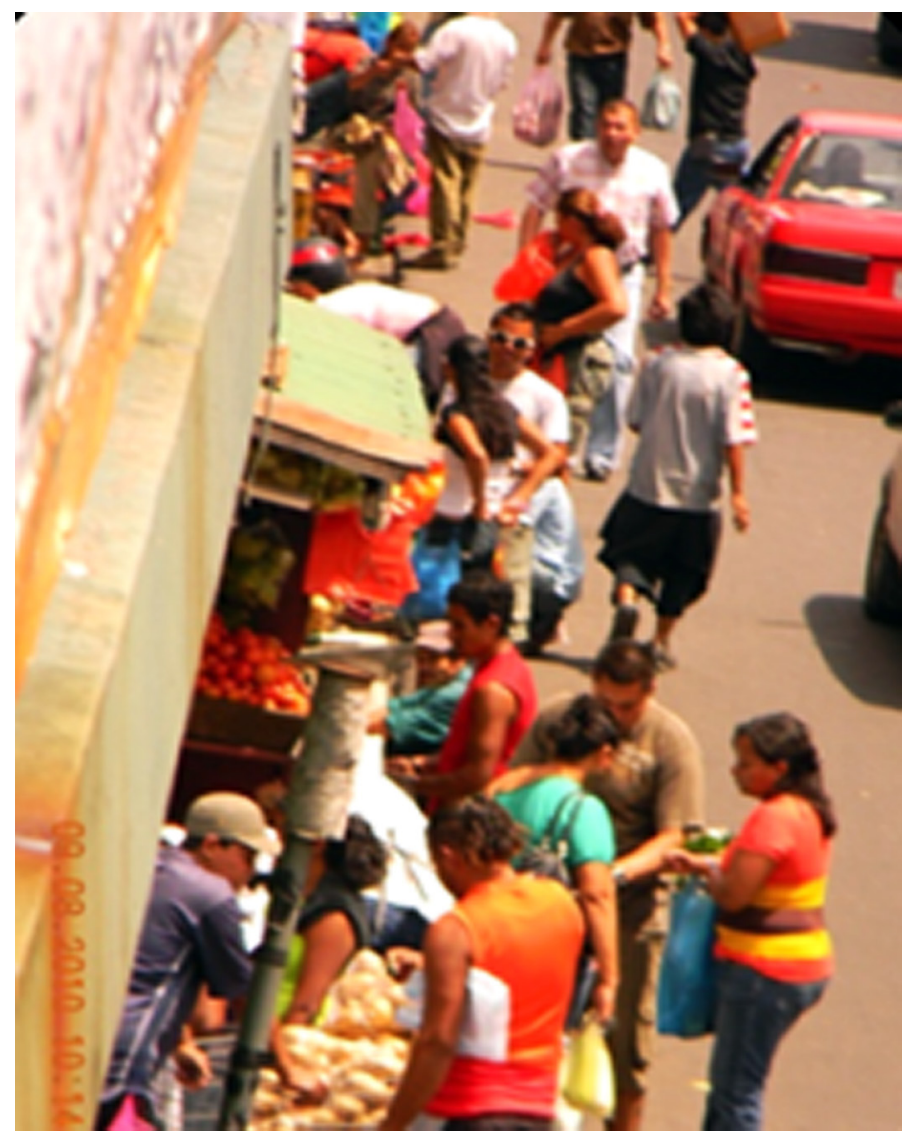

Figura 1: Ambiente de la economía popular (tomado de: Araya et al., 2011).

para confirmarlo y la venta se concreta o se pierde. La oferta es variada, los precios se mantienen - iPa!, ¿a cuánto la manzana? -Cinco en quinientos, solo calidad. ¿Cuántas quiere? -Solo para calmar la tripa deme dos. ¿Dos tejas verdad? -Sí, sí, escójala usted, solo bueno.

Intercambio comercial, de gestos, miradas e intuiciones. Se comunican avisos de presencia de autoridad, de gente extraña, todo aquel que sea visto como otro y sea nuevo en el contexto es recubierto de miradas que analizan vestimenta y actitud. Conversaciones que se arremolinan y forman cuchicheos que irónicamente ensordecen.

Las calles se transforman ante los ojos en una barriada donde la gente trabaja, pero también come, juega, socializa, cría a los hijos... vive. Notoriamente en ellas no hay casas ni parques; el espacio se delimita por zonas de trabajo donde ellos y ellas se colocan. Espacio que sirve también para descansar; las calles para jugar, conversar, correr y moverse hacia otros lugares. Barrio que igual se organiza, tiene movimiento, vecinos que lo integran. Hay chiquillas y chiquillos en uniforme sentados en aceras que bien podrían ser 
los jardines, adornados con los colores de los ramos de apio, culantro, torrecitas de chiles dulces y plátano maduro. La calle es el espacio donde se desarrolla su cotidianidad. Están tan familiarizados con el lugar que toda su dinámica es parte de su vida y de la reproducción de la misma. Se relacionan con sus padres, amigos, compañeros de labor, sus vecinos.

Esperanza vende en ocasiones junto a su hijo de seis años (Figura 2). A inicios de 2011, él pasaba el tiempo en la calle con su mamá, porque las clases no habían empezado y como toda la familia se dedica a la venta ambulante, él tenía que pasar el día ahí. Al inicio del curso lectivo, en febrero de 2011, ver al chico en las tardes todavía era escena frecuente. Se la pasaba curioseando, haciendo muecas y explorando la calle donde pasa el día con sus papás. Esperanza dice que repetidas ocasiones el Patronato Nacional de la Infancia la ha interrogado sobre los motivos que hacen que el niño permanezca en la calle. Ella refuta las críticas diciendo que el niño sí estudia, pero la mitad del día no tiene quién lo cuide en su casa y pagar para que lo cuiden es demasiado costoso, y ella no lo puede costear. Por eso se debe adecuar las normas familiares para dar sustento a todos los miembros, pero también protección y bienestar.

El espacio público donde se desarrolla la vida de los vendedores ambulantes, el barrio en la ciudad, es el San José que la mayoría vemos como zona de paso, de tránsito (Figura 3). Muchas veces definido por la mayoría de personas que lo transita como caótico, desordenado, sucio, acelerado, donde se desplazan miles de extraños, que a la vez están relacionados, es:

...una reunión de extraños, unidos por la evitación, la indiferencia, el anonimato y otras películas protectoras, expuestos, a la intemperie, y al mismo tiempo camuflados, mimetizados, invisibles. El espacio público es vivido como espaciamiento, es el escenario de una estructura hecha más de instantes y de encuentros que de instituciones que singularizan la sociabilidad urbana (Delgado, 2000, p. 46).

Esos instantes que arman la ciudad son los imperceptibles por las miradas rápidas. Se debe hacer un ejercicio más profundo y observar con detenimiento los rostros, palabras, gestos de esos a los que acusa la policía municipal, la prensa y la opinión pública de invadir el espacio público y entorpecer el libre tránsito.

En un espacio designado como barrio se atienden otras necesidades básicas, entre ellas la comida, en las medias mañanas y tardes no faltan los vasos desechables con café y los cigarros encendidos. La mayoría de los vendedores son fumadores constantes y los paquetes arrugados de cigarrillos, mayormente Delta Duro, Marlboro y Derby, son compartidos entre los compañeros y compañeras que están ubicados más cerca. El olor es penetrante y se mezcla con el festival de aromas que ya de por sí hay en la calle: los condimentos que se venden en el Mercado Central, las cloacas, el humo de los carros, transeúntes ataviados en perfume, vegetales podridos, sudor, culantro fresco. 


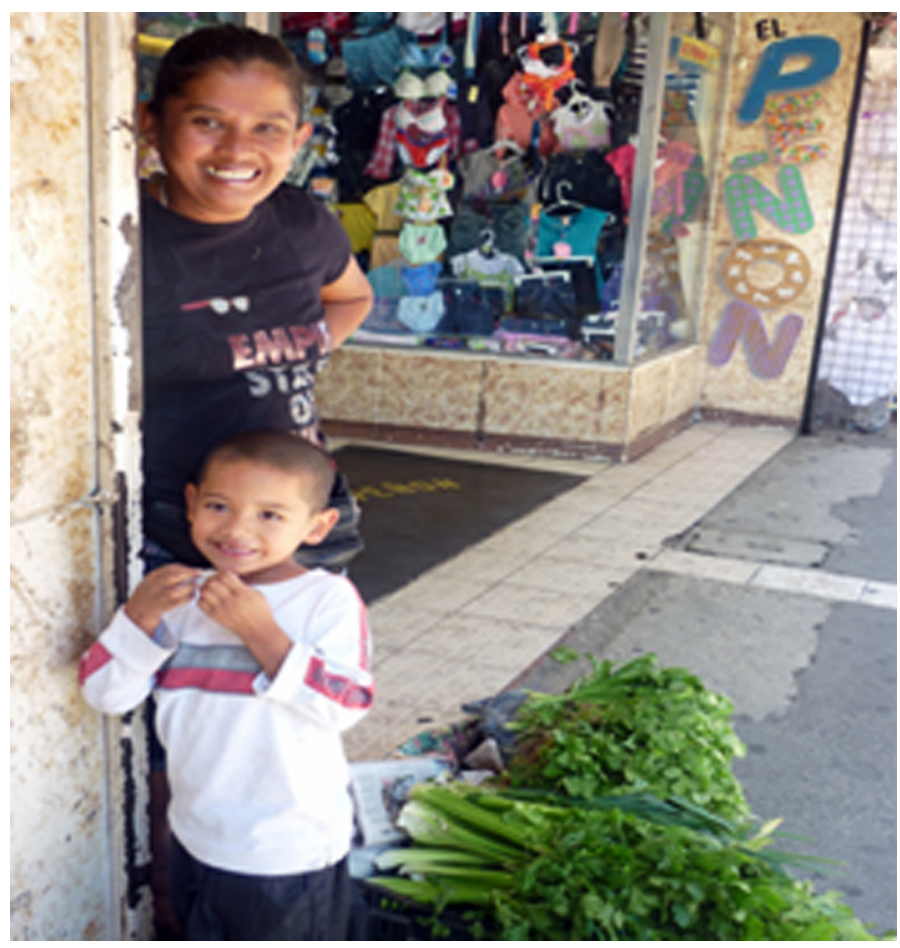

Figura 2: La convivencia con los hijos en las calles, doña Esperanza con su hijo (tomado de: Araya et al., 2011).

El café lo reparte una señora que no es vendedora de vegetales ni frutas. Recorre las dos calles con un termo grande hasta el "tope" de café negro. Carga el termo en la espalda, como un bulto (mochila) y a un lado una canasta con lo que parece ser emparedados. Lo vende a la mayoría de los vendedores que están laborando en el momento de su visita. Es un comercio ambulante que se genera a partir de las ventas ambulantes, posibilidades que la economía popular genera. Ventas dentro y por las ventas ambulantes, que posibilita oportunidades de sustento a todas las personas que se involucran en la red que se teje alrededor de la satisfacción de necesidades (Figura 4).

La hora de la comida la determina cada vendedor (Figura 5), cuando "el hambre aprieta" es un descanso para conversar y como la mayoría la departen simultáneamente, la oferta baja de tono y las charlas y bromas afloran.

Los almuerzos son variados, La Machita cuenta que ahí se come cuando hay hambre y siempre "a la intemperie". La comida se trae de la casa y se comparte, porciones de pan, el gallito ${ }^{1}$ que se trae de la casa a veces alimenta a dos personas. Es común ver a dos o más vendedores compartiendo bollos de pan con mantequilla o frutas de las que ellos mismos venden.

1 Bocado pequeño de comida, especie de entremés. Generalmente se le llama así a los almuerzos ofrecidos a las visitas en las casas. 


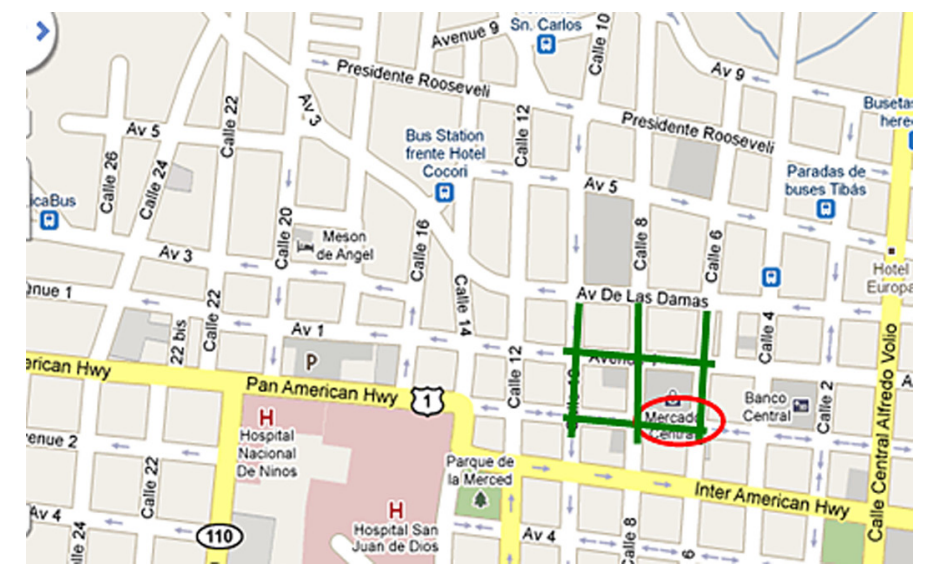

Figura 3: Distrito La Merced, Casco Urbano Central de San José. Fuente: Elaborado con base en Google Maps.

Esperanza parece ser más práctica para su alimentación y la de los miembros de su familia. Ella prefiere comprar el almuerzo en algún restaurante chino de la Avenida Segunda o en alguna soda cercana. Ella vela por su comida, la de su hijo mayor, su hijo menor que aún está pequeño y su compañero. Dice que hace cálculos para que cada almuerzo le salga en mil colones (dos dólares) aproximadamente para gastar menos de cinco mil colones al día. Este sistema se le hace más cómodo porque cargar los almuerzos desde la casa es complicado, además no existen lugares para poder calentar la comida, asegura que lo que gasta comiendo afuera es como si hiciera el gasto de comprar más diario² para la casa, por eso no lo ve como un gasto extraordinario.

Esos espacios de comida son momentos de socialización y comunicación, en condiciones muy diferentes a las que normalmente se piensa a la hora de alimentarse. El humo de los vehículos, el ruido de pitos, miradas extrañas forman el ambiente para el almuerzo, donde se aprovecha para dialogar con los hijos, si están cerca o con los compañeros y compañeras de labores.

\section{Manifestaciones de la economía popular en calles 6 y 8}

Los componentes del capital social -confianza, normas y redes- tienden a reforzarse entre sí, con lo que se establece un círculo virtuoso que produce equilibrios sociales con altos niveles de cooperación. El sociólogo francés Pierre Bourdieu dice que "el capital social está constituido por la totalidad de los recursos potenciales o actuales asociados a la posesión de una red duradera de relaciones más o menos institucionalizadas de conocimiento y reconocimiento mutuos" (Bourdieu, 2003).

En las ventas ambulantes, el capital social se manifiesta mediante los recursos que se generan a partir de la pertenencia a un grupo, ese capital es de utilidad para todos los vendedores y vendedoras como respaldo al verse reconocidos en otros que comparten su actividad y forma de vida.

2 Comestibles comprados por períodos para el gasto del hogar. 


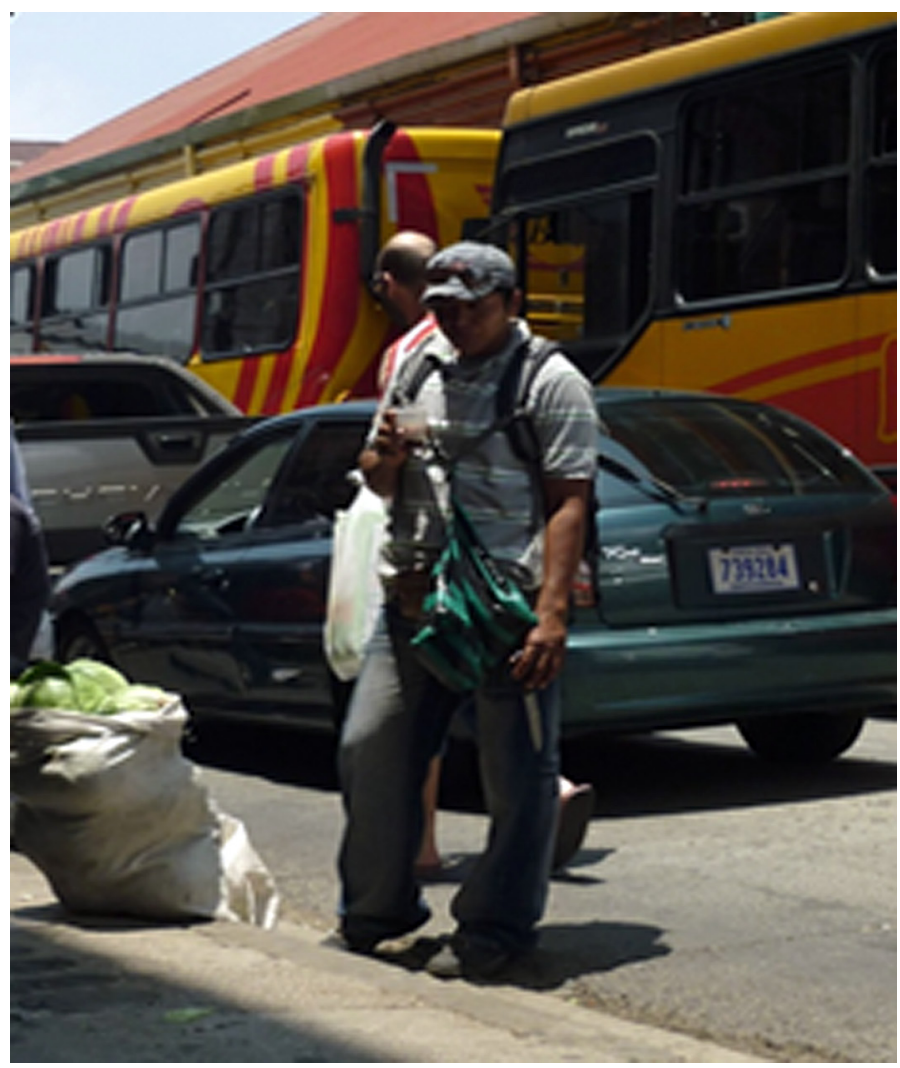

Figura 4: Hora del café de los vendedores ambulantes (tomado de: Araya et al., 2011).

El sentimiento de confianza dentro del grupo también los obliga de cierta manera a cimentar acciones de reciprocidad y cooperación, ya sea con los avisos de presencia policial, el compartir en las horas de comida o la confianza para pedir ayuda o representación que incluye también a las figuras de autoridad dentro de la organización (en este caso los que llevan más años en el oficio, etc.) como fuera de ella (empleados y dueños de los chinamos ${ }^{3}$ y policías municipales). Sobre la reciprocidad en la calle:

Las normas efectivas constituyen formas de capital social porque generan confiabilidad en el ambiente: favorecen o restringen determinadas conductas. Por un lado, las normas más valoradas son aquellas que favorecen los intereses colectivos por encima de los individuales, ya que ello ayuda a construir beneficios comunes o resolver problemas identificados a partir de propósitos en común (Gordon, 2004, p. 8).

Para que se pueda construir capital social y que este sea sustento de la economía popular, como forma de reproducción de bienes materiales pero también de la vida, es necesario que en las relaciones que se

3 Puestos de armazón sencilla de metal o madera con techo de zinc dedicados a la venta de frutas y verduras en las aceras de San José. Cuentan con patentes estacionaras extendidas por la Municipalidad de San José. 


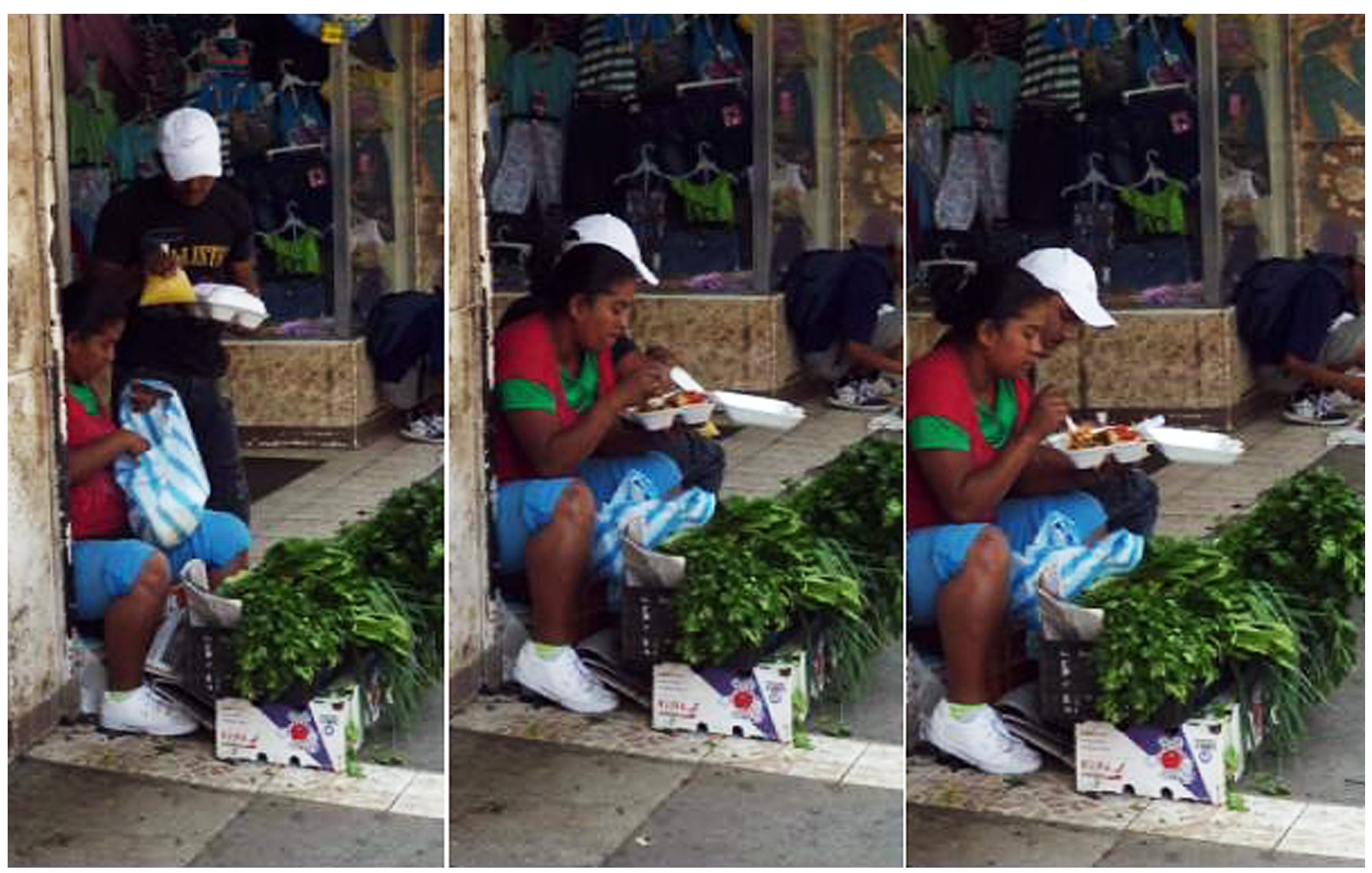

Figura 5: Hora de almuerzo de los vendedores ambulantes (tomado de: Araya et al., 2011).

establecen sea posible la existencia de un sentido de unidad más o menos duradero, compartido por el grupo en común y que este sea reconocido por quienes participan de la relación.

En las ventas ambulantes, el capital social se concibe como los recursos que se construyen a través de los lazos sociales de solidaridad, reciprocidad y compromiso, los cuales están presentes en las formas de organización utilizadas por ellos y ellas, y en la satisfacción de sus diferentes necesidades a través de la actividad económica de la venta ambulante. Operacionalmente, el capital social puede ser definido como los recursos arraigados en redes sociales a los que unos actores acceden y los utilizan para acciones específicas. A propósito de este intercambio:

La reciprocidad es la norma más importante en términos de capital social y se le considera de dos tipos: la reciprocidad equilibrada o específica y la generalizada o difusa. La primera se da cuando ocurre un intercambio de objetos o bienes cuyo valor se considera equivalente (un favor por un favor, un regalo por otro). Además, 
ese intercambio, aunque pueda repetirse, se acota como un evento específico en el tiempo. La segunda establece una relación permanente y continua de intercambio y, aunque en un momento dado puede no ser equivalente, mantiene la expectativa de que los beneficios serán mutuos y, a largo plazo, equiparables (Gordon, 2004, p. 16).

Además, dentro de la dinámica del ambulantaje, se manifiestan los vínculos de solidaridad de los que escribe Bajoit (2003), donde existe redistribución de los bienes materiales y de recursos de existencia pero también se da un reconocimiento de la identidad que caracteriza al grupo de vendedores y vendedores ambulantes. A partir de esa identificación, se crean grados de confianza los cuales sirven de cimiento para la creación de nuevas formas de reciprocidad.

Mercedes Sarría (2005), antropóloga brasileña, hace especial énfasis en la espontaneidad de las acciones de solidaridad, y precisamente los relatos de La Machita reafirman esa noción. Se ayuda a quien lo necesite cuando lo necesite, no hay un código de acción definido ni un plan de emergencias trazado, se trata más de tomar las decisiones correctas en el momento requerido, si es en un decomiso o en un enfrentamiento directo con la policía o la amenaza de la delincuencia de la zona. Experiencias con otros vendedores han dejado ver la extensión de la redes de solidaridad. Ante la ausencia de una casa para una familia completa de miembros del gremio, la búsqueda de un lugar seguro inicia. Entre números de teléfono, disponibilidad de albergues se crea una estrategia de ayuda para salvaguardar a una familia que depende en su totalidad de las ventas para salir adelante:

Uno siente que tiene que meter mano en estas cosas porque son compañeros de la calle y uno los ve todos los días. Aunque sea buscarles un cuartito para que no anden en moteles con las chiquitas porque ese ambiente no es bueno para ellas. Yo no me puedo hacer la loca con eso, uno también ha pasado por esas situaciones y sabe lo difícil que es (Esperanza, comunicación personal, 7 de febrero, 2011).

El ejemplo anterior refiere a una situación específica donde la solidaridad entre ellos y ellas se ostenta. Lucía y Carlos, con tres hijos pequeños, en febrero de 2011 necesitaban encontrar una casa para alquilar, pues tenían dos semanas de estarse quedando en habitaciones de moteles de calles 6 y 8, en San José. Por problemas económicos los habían desalojado de su antigua vivienda y no habían podido encontrar un lugar para establecerse que sus ingresos provenientes de las ventas les permitieran costear. Esta situación trascendió a los oídos del gremio, pues debían trabajar para darle solución al problema de la familia, se buscaron alternativas como albergues y centros para indigentes, pero fueron rechazados por tener un bebé de meses como miembro de la familia. Finalmente, los esfuerzos y búsqueda de contactos de los demás vendedores y vendedoras, especialmente Esperanza, lograron encontrar una casita en los barrios del sur josefino, dando un sentimiento de tranquilidad al grupo, pues salvaguardar la seguridad de los compañeros es parte fundamental del desarrollo de la cotidianidad. 
Es importante rescatar que el espacio público es un producto social y que independientemente de para qué y quién fue diseñado, su uso puede ser diferente, a partir de los niveles de apropiación simbólica y real que puedan hacer de él los habitantes, así como de las características propias, físicas, del espacio en sí mismo. Esta aproximación facilita la entrada para reconocer las dimensiones en las cuales los espacios públicos pueden contribuir a la expansión del capital social (Dascal, 2004), en este caso asociado al ejercicio de la venta ambulante, no solo vista como trabajo para generar recursos de subsistencia, sino como una manera de crear formas de organización que se transforman en modos de vida:

Como se puede apreciar, lo que los ferianos "heredan" no es sólo un tipo de ocupación ("comerciar", "trabajar en la calle"); también dan continuidad a un modo de asociación ("en familia", "por generación", "red de familias ferianas") y, sobre todo, a una forma de relación con otros ciudadanos en un espacio público que no es ni estatal ni eclesiástico (Salazar, 2003, p. 89).

\section{La perspectiva de la economía popular}

La economía popular trasciende el significado comercial de las ventas ambulantes, refiere a la reproducción de la vida como tal y envuelve cantidad de relaciones asociadas a planos de función, organización, estructura y relaciones, no se reduce sólo al intercambio de bienes por dinero. Para el caso de los regatones, como los llama Salazar (2003), la economía popular se podría definir como una actividad económica envuelta de prácticas sociales que les posibilita satisfacer sus necesidades básicas, tanto materiales como inmateriales, mediante su fuerza de trabajo y los recursos disponibles en el medio.

La particularidad de esta forma de economía reside en que la venta ambulante se ha transformado en su modo de vida, no se reduce a una alternativa para sobrevivir en medio de una sociedad capitalista excluyente. Es un oficio que se traspasa generacionalmente, se aprende, se vive y se disfruta a pesar de las condiciones difíciles que lo rodean y que se manifiesta de forma diferente en cada uno de los individuos que la experimentan.

La Machita, de 67 años de edad, cuenta que desde los 60 años que tiene de ser vendedora, la calle ha sido como su otra casa. Los compañeros cambian con los años, algunos se mantienen hasta hoy, como en su caso. Según su experiencia, ahí entre todos avisan cuando la Muni anda haciendo operativo, lo que hacen es decomisar la mercadería. Años atrás, en su juventud, el garrotazo ${ }^{4}$ era un hecho, para ella, dedicarse a las ventas en estos tiempos es más llevadero. Reitera su apego a la calle, pues desde los ocho años se dedica a ofrecer ajos y chile dulce -o lo que se pueda, según ella misma cuenta- en las calles de San José.

4 Violencia física por parte de los policías municipales. 
El compañerismo es parte fundamental del trabajo que se realiza. Es un juego de "estira y encoje" donde el individualismo no es bien recibido y no aporta beneficios al trabajo realizado. Hay una constante negociación para las estrategias de venta, distribución del espacio, cuido recíproco y muestras de apoyo que son dadas esperando recibirlas de vuelta en el momento que se necesiten. Al ser un ambiente cargado de tensión, contar con cierta seguridad de apoyo y resguardo aliviana un poco el peso que genera estar en alerta todo el día, esperando la llegada de la Policía Municipal y salir corriendo, muchas veces sin rumbo fijo. A pesar de las duras condiciones del trabajo, el apego por la calle aflora y deja ver el gusto que se desarrolla por el trabajo.

Yo desde carajillo vengo aquí, aquí me he criado. Toda la vida he estado en eso. Fui tonto porque por estar vendiendo no terminé la Universidad y que conste que si tuve la oportunidad de estudiar. Pero que va, a mí me encanta estar aquí. Vendiendo le di el estudio a mis hijos. Si a mí no me gustara estar aquí pues ya hubiera jalado desde hace rato... pero véame... aquí sigo (Conrado, comunicación personal, 7 de febrero, 2011).

Las muestras de solidaridad, la construcción de redes sociales, la acumulación de códigos que permiten una comunicación fluida y específica y las relaciones entre ellos y ellas son experiencias que forman parte de la reproducción de la vida en las calles alrededor de las ventas ambulantes.

Para visibilizar las formas de organización dentro de la estructura de los vendedores y vendedoras ambulantes, alrededor de la economía popular, se debe tener en cuenta la estructura de esas organizaciones y su funcionamiento (vendedores, trabajos especializados, funciones dentro de la organización, relaciones). Por lo tanto, las experiencias de su cotidianidad se transforman en un conjunto de actividades que cumplen siete funciones básicas:

\section{1) Función cultural}

Existen espacios de reunión social, pues al reunirse diariamente se crea un sentido de unidad. La Machita y Esperanza reflejan la construcción de normas y valores conjuntos dentro de la venta ambulante, su comunión con los demás miembros del gremio, y la constante creación de normas que regulen al actuar crean un sentido de cohesión. Ese compartir se fomenta con el día a día y el estar allí en la calle, la barriada alrededor de las ventas "permite desarrollar una identidad y una cultura sociales que, en un nivel básico, producen satisfacciones, solidaridad, protección y [...] vida" (Salazar, 2003, p. 91). El espacio entre los vendedores es de escasos tres metros, inevitablemente en el desarrollo de la jornada de trabajo cada quien

se involucra en las actividades del otro y al compartir la misma actividad económica se van moldeando normas que hacen más llevadera esa convivencia. 
Las normas establecidas son claras, como dice Esperanza, para que un vendedor sea aceptado dentro del grupo y goce de los beneficios de protección y solidaridad, debe primero tratar bien a sus compañeros de trabajo, esto incluye el uso de un lenguaje respetuoso (sin malas palabras, ni groserías) y la disponibilidad de ayudar a los otros miembros cuando sea necesario. El buen trato debe extenderse también a los clientes, de forma verbal y también en cuanto a las acciones, están prohibidos los asaltos a los clientes o abusos de precios. Quien desee unirse a las ventas debe tener claro también el respeto por el espacio de la venta y no repetir los productos, los cuales se distribuyen por secuencias, si Esperanza hoy está vendiendo chiles, el compañero o compañera que esté continuo a ella debe tener otro producto para no crear una competencia desleal, asimismo, debe mantener una línea de precios similares.

\section{2) Función psicológica}

Al contarse problemas personales y de trabajo, asuntos que les preocupa. Ángela llegó un día en la mañana a calle 8 , pero no a trabajar, ese día venía de los Tribunales de Justicia, ya que dictaban sentencia a un policía que años atrás la había golpeado en un operativo y le fracturó el brazo. Al salir, se fue directo a contarles a sus compañeros, entre ellos Conrado (quien vende desde niño), que ganó el juicio y además, le deben pagar una indemnización de más de un millón de colones. La rabia se saborea en el relato y el apoyo de los compañeros no se hace esperar, el regocijo de Ángela era evidente en el apretar de sus dientes y la agitación de sus brazos. Sentir que le gana una pequeña batalla a la figura que constantemente la amenaza es un placer que debe compartir con sus compañeros. El hecho de afirmar esa victoria en el mismo espacio donde ocurrió el incidente y donde se desarrolla, además, la mayor parte de su vida cotidiana, da un valor enorme a la capacidad de construcción de relaciones y actividades de la economía popular.

\section{3) Función social}

Toda la jornada de trabajo se mezcla con las conversaciones entre compañeros de cómo manejarse en las calles y el avance de la labor diaria. Tras jornadas de doce horas o más, se necesita con quién conversar, compartir experiencias alrededor del trabajo y crear vínculos que permitan un desarrollo saludable del día laboral. Pero además, se crean las relaciones como la de vendedor-comprador, que de nuevo trasciende el intercambio de productos por dinero, y hace recordar que esta barriada está inserta en una ciudad donde se debe hacer un esfuerzo por reconocer al otro.

http://revistas.ucr.ac.cr/index.php/antropologia 


\section{4) Función política}

Que se ve mayormente reflejada en la organización para actuar frente a la presencia policial y las relaciones que tienen con los entes punitivos, e igualmente en la apropiación del discurso de legitimación de la venta ambulante. Aquí es necesario resaltar que la organización de los vendedores y vendedoras ante la presencia de la Policía Municipal es autogestionada y espontánea en un principio, pero los silbidos, gritos de iHojas secas! $!^{5}$ miradas se convierten en estrategias que se elaboran o configuran en la práctica misma.

Existen asociaciones conformadas, ASPROVEN, AICA, ACOBA y ASOVEIN son las más mencionadas entre los integrantes del grupo más viejos. Estas asociaciones están debidamente reconocidas por la Municipalidad de San José.

Noé ha estado vinculado con esas asociaciones desde sus inicios en la calle, por su experiencia, dice que estas son las que velan por derechos del grupo ante las autoridades municipales cuando han existido enfrentamientos, desalojos y negociaciones. Actualmente, él está vinculado a la administración del mercado del antiguo Registro Civil, donde están ubicados más de cien vendedores y dónde él tiene un negocio propio. Aunque este mercado no esté ubicado en calles 6 y 8 , es un ejemplo claro del empoderamiento político que han adquirido. La creación del mercado en el edificio del antiguo registro es muestra de una forma de organización específica para enfrentar condiciones adversas ante necesidades primarias como son la obtención de recursos para la subsistencia.

Algunos de los vendedores con más años de ejercer ésta actividad económica, no se sienten representados por esas asociaciones y sus apreciaciones dejan ver molestia y opiniones divididas acerca del trabajo que hacen por representar a las personas que ejercen las ventas ambulantes.

Esas asociaciones lo que hacen es ver a ver como recogen plata para beneficio de ellos mismos. Cobrando cuotas para esto y para el otro ya hay unos que tienen negocios propios en ese mercado y los que salen beneficiados son familiares o amigos de ellos mismos. Así fue antes de lo del mercado, con las ferias y con la rifa de los lugares del antiguo registro. Antes hasta cuota para oficina pedían, y uno diay lo pagaba, pero yo igual nunca me he sentido representado por ellos (Conrado, comunicación personal, 23 de febrero, 2011).

5 Frase utilizada por los vendedores ambulantes para avisarse unos a otros de la presencia de la policía municipal.

Cuadernos de Antropología 2014, 24(2), 73-95 
Conrado sin titubear prefiere asegurar sus derechos por él mismo, sin tener que ser alguna asociación quien lo represente, delimitando su espacio y buscando la mejor manera de proteger su oficio y si debe protestar por algún abuso lo hace directamente, sin buscar intermediarios.

Existe una organización popular para los momentos en que ellos enfrentan decomisos y para protegerse de la policía, esto evidencia parte de ese gran concepto de economía popular, que tiene dentro de sus fines el de proveer la sobrevivencia y reproducir el modo de vida. Paradójicamente, la irrupción de la policía es un detonante que impulsa a la organización de esta economía, pues la creación de estrategias para evadirla y buscar espacios de seguridad para ejercer las ventas, deriva en una organización estructurada y practicada por ellos mismos.

\section{5) Función económica}

Que refiere al mercadeo alrededor de los productos que se venden, dónde comprarlos, a qué precio venderlos, dónde guardar la mercadería. Las estrategias para la venta son simples pero efectivas, en un lapso de veinte minutos Esperanza o Conrado pueden ganar de dos mil a tres mil colones. Los chiles, manzanas, ajos están expuestos en sacos blancos extendidos en las aceras o cajas plásticas de colores que una vez se utilizaron para apilar refrescos.

Esperanza considera que los lugares donde se ubican les dan buenos resultados, en relación con las ventas, por lo que fomentan de manera constante la seguridad en la zona para comodidad de los clientes, con vigilancia interna entre ellos mismos (aspecto que también es una de las normas que se deben seguir para ser aceptado dentro del gremio). Para optimizar las ventas, cada uno y una trata de mantener cierta constancia en la oferta de sus productos, para que los clientes se familiaricen y retornen a hacer sus compras, así sabrán dónde encontrarlos y qué producto adquirir, lo que también propicia que algunos clientes se vuelvan fijos y establezcan relaciones más cercanas con ellos. El mantener los precios en un nivel justo y el buen trato al cliente son su fórmula de mercadeo; sin importar qué producto se ofrezca, la estrategia no parece variar.

Al familiarizarse con las ofertas, es notable que los precios de los vegetales son considerablemente más baratos que en otros establecimientos como supermercados. Por ejemplo, Lucía ofrece paquetes de quince chiles dulces en setecientos colones. En un supermercado, cada chile dulce se consigue en alrededor de ciento veinte colones, según la temporada y demanda del producto. Esta es una de las razones por lo que la clientela de los vendedores ambulantes es constante y creciente, y ellos mismos no escatiman en afirmar que es uno de los beneficios que aportan a la sociedad.

Aunque sea el trabajo de nosotros, y la gente a veces crea que no es un trabajo como el de ellos, yo sí creo que nosotros damos un beneficio a los clientes. Usted no va a encontrar un paquete de chiles en quinientos pesos en el supermercado, tal vez 
en una verdulería sí. Pero igual es más fácil comprarlo de camino a la parada del bus. Es el trabajo de nosotros, pero si se le puede dar un beneficio a la gente mejor (Esperanza, comunicación personal, 26 de enero, 2011).

Para Esperanza está claro que su trabajo crea un beneficio directo para la sociedad. Esa idea de beneficiar el bolsillo de sus clientes está presente en las estrategias de venta y mercadeo de sus productos. Además, ella está consciente de las situaciones difíciles que genera la estrechez económica de la mayoría de los costarricenses y parte fundamental de su motivación para trabajar en la venta ambulante, la genera poder brindar un servicio que le ahorre dinero a sus clientes.

Los productos que ofrecen tienen distintas procedencias. La Machita había señalado que ella prefería comprarle a un distribuidor que llega a San José en las primeras horas de la mañana, así como otros prefieren comprar su mercadería en las llamadas bodegas o verdulerías cercanas a los mercados Borbón y Central, que son una especie de verdulería, pero a grande escala, que revende mercadería de productores directos o de los mercados aledaños. Esperanza prefiere comprarles a productores, agricultores que vienen a vender su cosecha alrededor de las cinco de la mañana a las calles josefinas en camiones grandes, procedentes de Cartago, Alajuela y diferentes zonas de San José.

Esa preferencia se debe a que al ser los productores de los vegetales y las frutas, crea un sentimiento de estar beneficiando directamente a quien los cosecha, eliminando redes de intermediarios que propician el alza en los precios, lo que deriva en tener que vender más caro a los clientes. Además, hay una razón de peso: estos productores dan el beneficio de pagar la mercadería al final de las jornadas laborales o hasta días después, además de dar en ocasiones la mercadería en concesión. De estos beneficios solo gozan los vendedores viejos ${ }^{6}$, los nuevos se ganan la confianza de los productores con el tiempo.

La mercadería que sobra al final del día a cada uno de los vendedores y vendedoras es almacenada en las bodegas ubicadas en las inmediaciones del Mercado Borbón, son sitios con tintes clandestinos, ya que también son refugio para ellos ante la amenaza de decomisos por parte de la policía municipal. En su mayoría, son antiguos parqueos privados de los edificios de los alrededores que brindan el espacio para hacerles más cómodo la ejecución de su trabajo.

\section{6) Función comunicativa}

Entre los regateros ${ }^{7}$ hay comunicación constante, se cuentan los pormenores del día y la semana, asuntos de último minuto. Lo que cualquier persona reproduce en su lugar de trabajo, con la diferencia de que ese espacio es para ellos y ellas, la calle. Al ser un grupo con una organización propia y espontánea, el estar

6Frase utilizada por los vendedores ambulantes para avisarse unos a otros de la presencia de la policía municipal.

7 Persona que vende al por menor comestibles comprados al por mayor.

Cuadernos de Antropología 2014, 24(2), 73-95 
informados de la situación general del día de trabajo es fundamental. No solo conocer los pormenores de la calle donde se encuentran sino de todo el espacio en general, tanto para estar alerta ante la llegada de la policía o para cambiar las estrategias o ubicación de la venta.

\section{7) Función educativa}

Aprenden sobre las ventas ambulantes, los compañeros con más años en el oficio transmiten su conocimiento a los demás, como Esperanza, que con un modo maternal, advierte de peligros y enseña a la familia conformada por Lucía, Carlos y sus tres hijos cómo desarrollarse en la calle, dándoles pautas de comportamiento con los clientes y entre ellos mismos y protocolos de seguridad. Lucía sale a vender con su esposo e hijas y al ser una familia joven deben ir adquiriendo experiencia de otras familias para poder desenvolverse en la calle, generar ingresos y conformar ese espacio en el contexto de educación para sus hijos.

Los saberes no solo se transmiten de vendedor a vendedor, los hijos que comparten con sus padres en la calle absorben todo el conjunto de normas y comportamientos que observan al estar allí. Valores para la vida en general. Otros vendedores transfieren a sus hijos el conocimiento del oficio, pues varias generaciones de su familia se han dedicado a las ventas ambulantes, haciendo de esto una herencia y no solamente un medio de subsistencia económica.

Todas las anteriores funciones se entretejen en dos ámbitos. Primeramente el económico, vinculado con la reproducción de la vida, desarrollando estrategias de trabajo y permanencia, lo que genera ganancias económicas que son intercambiables en la esfera económica normativa, pero que también propician procesos de socialización del conocimiento, la cultura, las relaciones afectivas. Aquí se contempla la creación de grupos de apoyo y organización, lo que da estructura y validación como grupo a los vendedores ambulantes.

Más allá de que su actividad sea para la creación de ingresos, dentro de esa economía se manifiestan acciones espontáneas de solidaridad entre La Machita, Conrado o Esperanza y en acciones a nivel colectivo organizadas a partir de la espontaneidad, con el fin de mejorar sus condiciones de vida (Sarría, 2005, p. 25).

El segundo ámbito refiere a la forma en cómo estos sectores permanecen y reproducen la vida y por lo tanto su existencia. Lo cual depende del contexto dónde se desarrollen y el panorama político que los envuelve.

De la mano con la función política, la noción de economía popular, da más herramientas para definir lo que sucede en el centro de San José. Posibilita también ampliar las vistas del discurso de exclusión social en Costa Rica. Luis Razeto (1990a, p. 56) cree que el potencial de la economía popular reside en poder visibilizar este tipo de actividad económica como una opción social, económica y política que toma fuerza con el debilitamiento de otras formas de vinculación con el mercado. Esto también permite romper con la 
idea de que las personas que se dedican a las ventas ambulantes lo hacen por mera necesidad económica, sin tomar en cuenta la tradición familiar del oficio, el apego a las calles y la dinámica urbana que los vendedores desarrollan.

La economía popular es un modo de vida, una expresión social y cultural relacionada con formas tradicionales y antiguas de economía y con un placer y deseo por estar en la calle. El sentimiento de libertad que contrasta con la persecución policial, que los comerciantes ambulantes transmiten al relatar su día a día, nace de ser sus propios jefes, la subordinación a otras personas no existe y la gestión y organización del día de trabajo corre por su propia cuenta. El mismo espacio de la venta es fluctuante, todo se acomoda a las necesidades del día y a las condiciones del momento. Como apunta Salazar (2003), existen ventajas innegables dentro de la venta ambulante: se tiene a favor la movilidad espacial y la libertad comercial. No se pagan patentes ni alquiler de locales comerciales y los costos de operación son significativamente más bajos.

El apego a los compañeros y el gusto que se desarrolla por la calle, hace que, a pesar de ser constantemente perseguidos por su condición de "ilegítimos", no se amedrente su gusto por el oficio, más bien lo acrecienta y hace que éste tome más fuerza y vincule a más personas con el paso del tiempo.

Dentro de la venta ambulante hay una racionalidad que involucra formas de organización para hacer frente a necesidades personales y sociales. Necesidades de subsistencia pero también de convivencia y desarrollo cultural, “organizaciones económicas, pero no economicistas” (Razeto, 1990b, p. 73). La participación de las personas en ellas implica no únicamente trabajar, producir, vender y comprar, sino todo un modo de vida, una práctica social y grupal compleja que tiende a ser integral; más que de "estrategias de subsistencia" habría que hablar de estrategias de vida.

La organización de los vendedores del centro de San José no es estructurada desde un inicio, se va conformando cuando los códigos y símbolos permanecen y se reproducen de la mano de la actividad económica. Las estrategias para conservar el trabajo y hacer llevadera la vida en la calle son creadas por cada integrante del grupo, adecuándolas a sus necesidades específicas. Conrado, entre risas pícaras, confesó que hace algún tiempo, ante el crecimiento de la población de vendedores en la calle y la llegada de más vendedores nicaragüenses, la esquina donde él se ubica para vender se empezó a congestionar. Como la Municipalidad no regula los espacios, se las ingenió para proteger su territorio: él mismo pintó de color amarillo la orilla del caño de la acera a tempranas horas de la mañana. Cuando los demás compañeros le preguntaron quién había hecho la demarcación, Conrado afirmó, vehementemente, que el Ministerio de Salud había llegado a "pintar" la zona como parte de un plan de seguridad contra emergencias, destinando esa esquina como segura, y por lo tanto, había que respetar la señal por motivos de seguridad y tenerla despejada. Al instante había recuperado la amplitud de su espacio de trabajo: "si yo no lo hubiera hecho, nadie iba a llegar a quitar el montón de nicas que se habían puesto en la esquina. Mire uno tiene que usar la cabeza para defender lo de uno... risas... y lo mejor de todo es que se lo creyeron" (Conrado, comunicación personal, enero 2011). 
Esta noción de economía popular está estrechamente vinculada con el capital social de Bourdieu (2003), antes expuesto, donde los relatos y vivencias de La Machita, por ejemplo, son los recursos que sustentan ese capital, pues existen lazos de parentesco y organizaciones dentro del mismo grupo. Dos de sus hijos se dedican a la venta ambulante en el mismo espacio, reproduciendo con el tiempo vínculos familiares y solidarios para la defensa de intereses y derechos no solo en el plano individual, sino colectivo. La noción de capital social dentro de la economía popular implica que los intereses no pueden ser meramente individuales, máxime cuando existen de por medio, vínculos de sangre y afinidad.

\section{Cuando quiebran a los vendedores ambulantes. La des-estructuración de la economía popular}

De un momento a otro las cajas de cartón y madera que están en las aceras y que contienen plátanos, chayotes o chiles se posicionan en hombros de los vendedores y entre el tumulto desaparecen (Figura 6). Seis policías -cinco hombres y una mujer- se acercan; con lentes oscuros y determinación, se dirigen hacia la esquina del Supermercado Koopers. Parqueos y tiendas se han convertido a través de los años en refugio ante la amenaza de un decomiso por parte de la policía municipal, que algún vendedor advirtió con un fuerte grito de ¡Hojaaaaaaaaaaaas seeeeeeeecas! Ese beneficio de refugio, se obtiene al establecer una relación de confianza entre los dueños de los locales y los vendedores, que se crea por el trato diario y la convivencia. A su paso, los policías van levantando cajas que algún hombro no pudo llevar, cartones y restos de vegetales que son depositados en el cajón de una patrulla tipo pick up.

Un aviso de alerta, que logra una movilización para evitar momentos de choque que puedan perjudicar la venta ambulante, sugiere que en las calles cercanas al Mercado Central existen organizaciones que trascienden los intercambios comerciales. No es una frase sacada de la manga en el momento, es un código que a lo largo de la evolución de las ventas ambulantes ha servido para prevenir de la amenaza de un quiebre ${ }^{8}$, o decomiso de mercadería por parte de la policía municipal. Esos quiebres son el punto de desestructuración de la economía del ambulantaje, pues al ser despojados de los vegetales y frutas, que son la fuente de su trabajo, se pierde un día laboral y la posibilidad de generar más ingresos. A la vez que el día de trabajo se ve interrumpido y la estructura cotidiana se desfigura. Ser vendedor entonces también se traduce en:

Estar sujeto a la persecución policial, al embargo de la mercadería, a una prisión eventual y al pago de una multa. Era fundamental, por tanto, que el regatón [vendedor ambulante en Chile] se moviera con sigilo, rapidez, astutamente, para eludir esa persecución; de lo contrario, todas sus ventajas comparativas se anulaban completamente (Salazar, 2003, p. 60).

8 Argot de los vendedores ambulantes. 

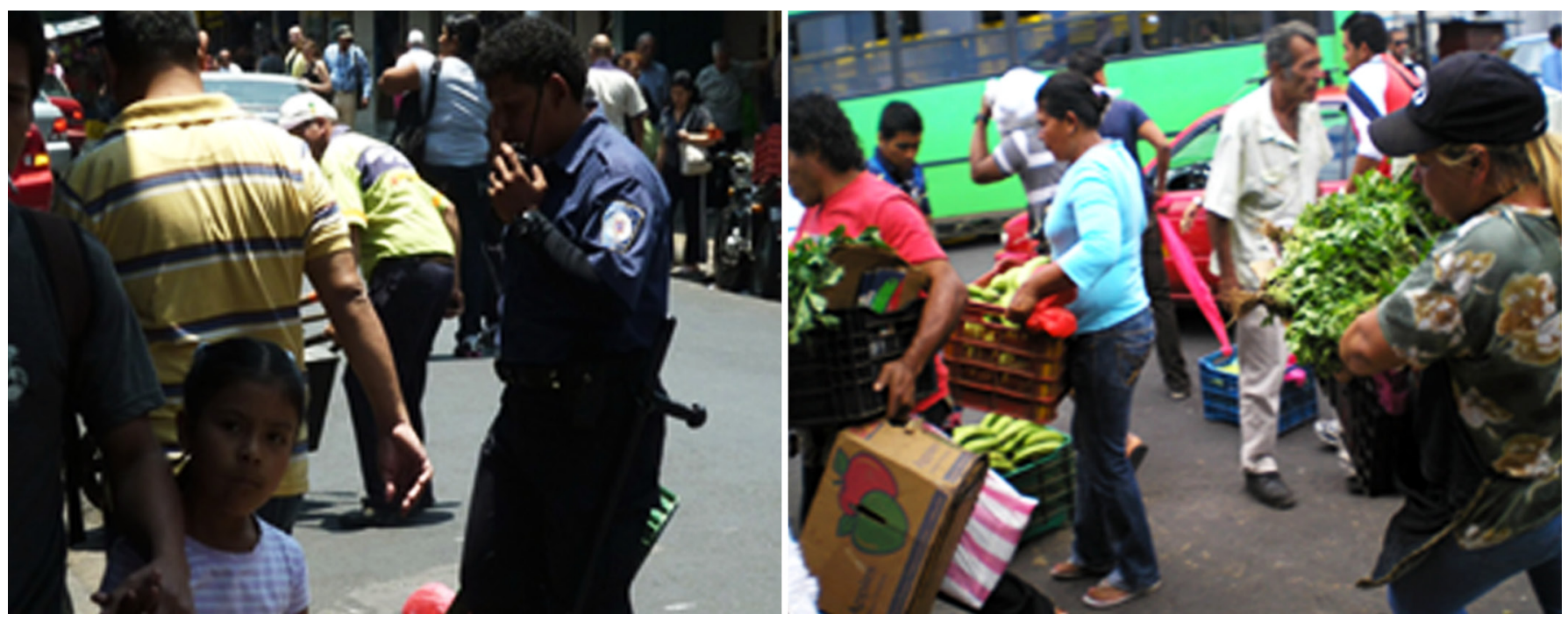

Figura 6: Decomisos de mercadería (tomado de: Araya et al., 2011).

En medio de estas situaciones, las muestras de apoyo y complicidad se observan en los gestos, miradas y movimientos de los cuerpos de los y las vendedoras, a lo largo y ancho de esas calles. Uno de ellos deja su espacio y mercadería al cuido de su compañero más próximo, no se sabe por qué debe ausentarse un momento, pero el favor que su compañero captura la atención de quién observa la escena. A su regreso, la mercadería sigue intacta y el agradecimiento es inmediato.

Luego de un quiebre -una caja de unas veinte papayas en esta ocasión- las ventas se disipan. Todos y todas se reúnen para presenciar la acción de la $M u n i^{9}$, seis policías esperan la llegada de la patrulla que va a cargar la mercadería confiscada. Entre gritos e insultos de una vendedora nicaragüense y un policía, $L a$ Machita espera que finalice el problema. Bromea con uno de los agentes e incluso la llaman por su nombre, en este caso particular, no hay tensión ni disputa entre ellos dos, aunque alrededor el ambiente es denso. Ella cuenta con naturalidad que los policías solo cumplen con su papel en la calle, que es básicamente el decomiso de mercadería. La violencia física aflora solo cuando los ánimos se calientan, y se abalanzan a golpes sobre los policías a defender el derecho de sus compañeros sobre sus productos. Las asociaciones que surgen de la venta ambulante no son solo entre los vendedores como integrantes del mismo grupo laboral, se crean vínculos entre las partes: vendedores y policías municipales construyen relaciones alrededor de la venta ambulante.

El trato de confianza de La Machita con el oficial municipal es una manifestación de las diferentes direcciones que puede tener el capital social (Bourdieu, 2003), en este caso se generan obligaciones y expectativas

9Diminutivo empleado por los vendedores y vendedoras para referirse a la Municipalidad de San José. 
recíprocas alrededor de una relación vertical (Coleman, 1988), pues en tanto el vendedor comprenda que el quiebre de la mercadería es parte fundamental del trabajo del oficial, habrá un ambiente de empatía y cooperación, evitando enfrentamientos violentos y garantizando respeto por el trabajo ambulante.

De esta manera, la relación entre vendedores ambulantes y policías municipales es cambiante, la cooperación y la tensión por el ejercicio del poder coexisten en las calles, como lo cuenta una de las vendedoras con más experiencia:

El otro día vino un gordillo que siempre anda por aquí (refiriéndose a un policía) y me quitó el gancho con todas las bolsas de chile que andaba. Tras de eso me metió la mano en las bolsas del delantal para ver qué más andaba. Yo le dije: "mi amor devuélvame los chiles, total ustedes los botan" y aunque otro compañero de él le dijo que no importaba que me los diera, me dijo que él estaba cumpliendo con el trabajo de él. Ya no les importa mucho que uno sea una persona mayor. Hasta le pedí que me dejara solo el ganchito y siempre se lo llevó. Uno entiende que es el trabajo de ellos (La Machita, comunicación personal, 6 de abril, 2011).

La Machita manifestó esta situación como uno de los casos en que se presenta la tensión que genera la autoridad policial. A pesar de que ella reconoce que los decomisos son parte del trabajo de los policías, resiente que algunas veces no se le respete su condición de adulta mayor, por la cual ella espera un trato más benevolente. Esperanza presenta otro tipo de relación con las autoridades. Ella denuncia abusos y malos tratos por parte de los oficiales, los relaciona con una figura de poder que los persigue y no respeta el trabajo que realizan, donde las buenas relaciones, según ella responden únicamente cuando hay chorizo ${ }^{10}$ de por medio.

Si fuera que solo lo quiebran a uno pues Diay no importa, bueno si... pero uno sabe que es lo que ellos tienen que hacer. Pero de eso a que lo maltraten a uno y hasta lo amenacen a uno con quitarle los güilas solo porque estén aquí con uno nada que ver (Esperanza, comunicación personal, 7 de febrero, 2011).

Las condiciones que hacen que ciertos días los y las policías municipales no hagan decomisos o respeten la venta, o existan lugares donde a pesar de su presencia no intervengan con el trabajo de los vendedores ambulantes, es una cuestión de organización mezclada con directrices municipales. Actualmente, las zonas de tregua ${ }^{11}$ ya no existen pero hay períodos y espacios en los que los policías deciden no actuar. Son lineamientos de alguna manera arbitrarios, pues los operativos se hacen a cualquier hora del día, como en todo espacio, hay versiones de lo que puede generar esa inconstancia en la vigilancia.

10 El chorizo en Costa Rica se define como las acciones o situaciones con tintes de fraude, tráfico de influencias o estafa.

11 Territorios definidos por la Policía Municipal en dónde los vendedores ambulantes podían trabajar con el "permiso" municipal.

http://revistas.ucr.ac.cr/index.php/antropologia 
Ah! eso es porque hay unos vendedores que ahora son distribuidores, ya ni trabajan en la calle, entonces con tal de que no los jodan, le pagan algo a los policías y esos con tal de hacer plata ponen la mano y los dejan tranquilos un rato. A veces son como mil pesos, ya con eso no los joden medio día, pero no es a todos, es solo a los que pagan (Conrado, 7 de diciembre, 2010).

En cuanto a las relaciones donde interviene algún ejercicio de poder, hay que reafirmar que estas son parte fundamental del capital social, y por lo tanto de la economía popular, pues las prohibiciones, el uso de la violencia y las normas de comportamiento establecidas son factores que determinan los tipos de relaciones que los vendedoras y vendedores construyen desde sus particularidades identitarias.

\section{Conclusiones}

A partir de la experiencia de estar en el espacio de trabajo de los vendedores ambulantes, las calles, y ser testigo de cómo hay todo un modo de vida alrededor de ésta actividad, se puede afirmar que existe una barriada inmersa en medio de San José, pues el espacio posee características que permiten definirlo de tal forma: la disposición de los espacios, la convivencia de las personas en el sitio, las actividades educativas, socializadoras y las acciones que satisfacen las necesidades hacen de las calles 6 y 8 el lugar de permanencia de ese grupo.

Al poder observar el desarrollo de un día laboral en ese espacio, las relaciones y organizaciones que se generan, es propicio afirmar que la venta ambulante no es solamente un trabajo que realizan personas en vulnerabilidad social y económica. Es un oficio aprendido y disfrutado, que ha posibilitado a varias familias el sustento de sus necesidades materiales, la oportunidad de dar educación a sus hijos y brindarles un ambiente seguro.

Ese ambiente es producto de una red de organización generada desde las ventas, organización que en un inicio es espontánea, pero que se convierte con el tiempo en código y tradición, pues los vendedores lo reproducen y transmiten a sus hijos, compañeros y colegas.

Los vendedores y vendedoras ambulantes siguen estando en San José porque a través del comercio ambulante se forjan una identidad, una cultura, moldean su trabajo y su forma de vida, un tanto independiente de la institucionalidad (existe a pesar de ella). Su permanencia se relaciona con "el esfuerzo y la inventiva personales y familiar; es decir: del "capital social” (Salazar, 2003, p. 92). El mismo Salazar aporta de manera puntual, el por qué a pesar de políticas gubernamentales que han intentado invisibilizar a los actores de la economía popular en San José (vendedores ambulantes, limpia botas, vendedores de lotería, entre muchos otros), los vendedores ambulantes siguen tomando las calles 6 y 8 para adornarlas con vegetales y frutas e inundándolas de aromas particulares: 
El comercio callejero permanece y prevalece no sólo porque su fórmula organizativa (la familia) y su existencia 'proscrita' permiten bajar los costos al mínimo y resolver la reproducción de la vida social en un nivel básico. Preciso es decir también que el comercio callejero permanece porque se basa en una relación flexible, libre y dialogante con el flujo callejero de la ciudadanía. Relación que se da en un espacio público sui generis: el constituido en la calle por los propios feriantes, en relación con pequeños montos de dinero, a mercaderías que para todos es la sal de la vida, y en torno a una transacción de fácil despacho. De modo que todos pueden asumir esa relación en un tono relajado, societal, de confianza, sin apremios mayores. Es decir: de un modo cívico (Salazar, 2003, p. 92).

La economía popular permitió realizar un acercamiento más humanizado a esta actividad tan recurrente y estigmatizada en Costa Rica. Resaltar todas las posibilidades que las ventas ambulantes generan, además de un intercambio comercial, permiten darles rostro a las personas que la ejercen y la viven, no solamente como un trabajo, como se mencionó anteriormente, si no como toda una estructura de vida, que se disfruta y se defiende ante la amenaza de las autoridades oficiales. Esta economía se vive en medio de una ciudad-escenario, donde después de hacer un ejercicio de observación detenida y detallada, las historias aisladas empiezan a transformarse en una "muchedumbre articulada... en la que podemos ver un proyecto de supervivencia popular que necesita de la ciudad y se apropia de sus espacios" (Salazar, 2003, p. 10), que ha dejado su estampa en cada esquina, calle y acera, pero también en la historia del San José por el que se camina hoy.

\section{Referencias bibliográficas}

Araya, G., Mejía, M., Solís, N. y Vega, K. (2011). Experiencias, vivencias e identidad de quienes se dedican a la venta ambulante de frutas y verduras, ubicados en las calles 6 y 8 del casco urbano central de San José, 2010-2011 (Tesis de licenciatura inédita). Universidad de Costa Rica, San José, Costa Rica.

Bajoit, G. (2003). Todo cambia. Análisis sociológico del cambio social y cultural en las sociedades contemporáneas. Santiago, Chile: LOM Ediciones.

Bourdieu, P. (2003). Las estructuras sociales de la economía. Barcelona: Ediciones Anagrama.

Coleman, J. S. (1988). Social capital in the creation of human capital. American Journal of Sociology, 94, Supplement: Organizations and institutions: Sociological and economic approaches to the analysis of social structure, S95-S120.

Dascal, G. (2007). Los espacios públicos y el capital social: aportes para comprender la relación entre ambos conceptos. Cuadernos de Geografía, 16, 19-26.

Delgado, M. (2000). Etnografía de los espacios urbanos. En D. Provansal (coord.), Espacio y territorio. Miradas antropológicas (pp. 45-54). Barcelona: Universitat Barcelona.

Gordon, S. (2004). Capital social: Una lectura de tres perspectivas clásicas. Revista Mexicana de Sociología, 66(4): 711- 747. 
Gúber, R. (2004). Identidad social villera. En M. Boivin, A. Rosato y V. Arribas (comp.), Constructores de otredad. Una introducción a la Antropología Social y Cultural (pp. 115-125). Buenos Aires: Antropofagia.

Razeto, L. (1990a). Área pastoral social de la Conferencia Episcopal de Chile (2 ${ }^{\mathrm{da}}$ ed.). Santiago: Programa de Economía del Trabajo (PET).

Razeto, L. (1990b). Organizaciones económicas populares. Las organizaciones económicas populares 1973 - 1990 ( $3^{\text {ra }}$ ed.). Santiago: Ediciones PET.

Salazar, G. (2003). Ferias libres: Espacio residual de soberanía ciudadana. Santiago: Ediciones SUR.

Sarría, A (2005). Economía popular, la otra economía. Recuperado de http://web.tau.org.ar/ 